\section{A knee in the neck of}

\section{excited delirium}

S ome call it an entirely manufactured psychological condition. The police believe it is not only legitimate, but potentially fatal.

The latter, though, may have a vested interest in perpetuating the notion that "excited delirium" is a valid medical condition, given the heat they've taken following last year's death of Polish citizen Robert Dziekanski at Vancouver International Airport after being shot by a taser, a hand-held weapon that uses compressed air to direct a jolt of electricity up to Io. 6 metres away.

Did Dziekanski die from "excited delirium" or multiple taser shocks? And what about the officer's knee pressed into his neck?

Dziekanski touched down in Vancouver on Oct. I4, 2007, following a I3-hour flight from Poland and for 8 hours roamed the immigration lounge, steadfastly insisting that his mother would soon meet him. She, meanwhile, awaited his arrival in the baggage claims area, while airport officials did nothing to ensure the pair could connect. Lost, confused and unable to speak English, Dziekanski used office chairs to build a makeshift barricade between a pair of glass doors as if to ensure that no one could remove him from his meeting place with his mother. Obviously frustrated, he began to throw computer equipment onto the floor and against a glass wall. The police were summoned and in stunning sequence of events captured on video by an eyewitness's cell phone, Dziekanski was pinned the floor, shot by a taser and eventually died.

Public outrage prompted the federal government to call an investigation into officers' use of tasers. The Commission for Public Complaints Against the RCMP [Royal Canadian Mounted Police] released an interim report on Dec. I2, 2007, recommending restrictions on the weapon's use. A coroner's inquest will commence in May.

The RCMP claim excited delirium was the cause of death. Media and civil liberties groups are skeptical about both the cause, and the condition.

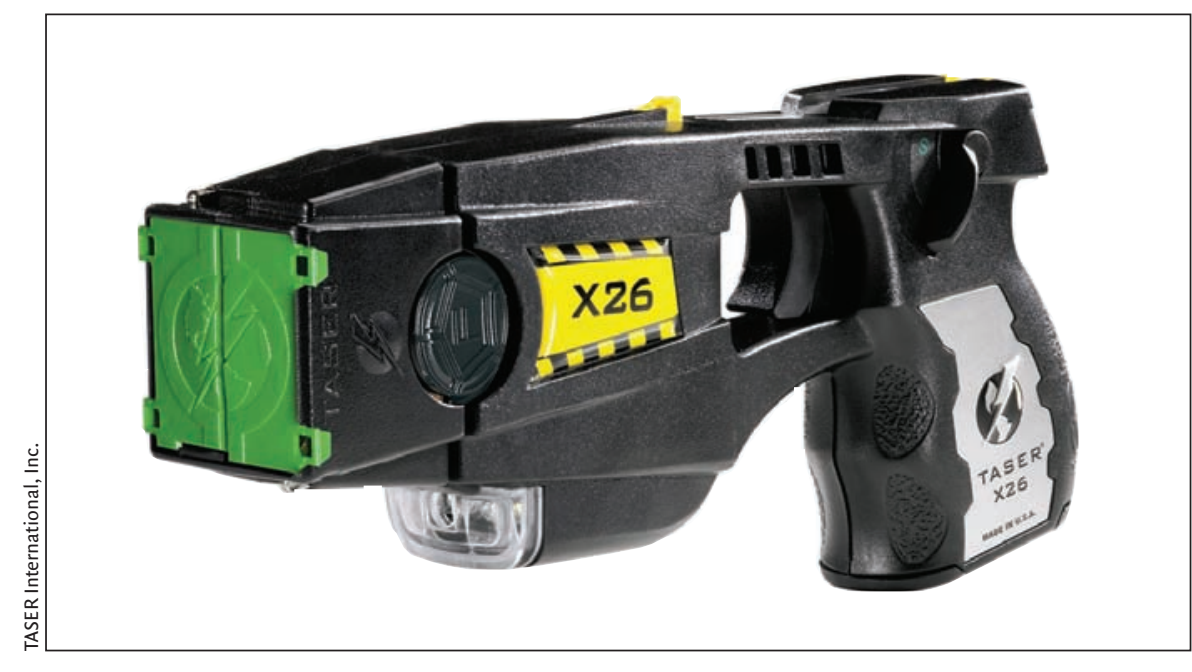

The TASER $X_{2} 6$ stores time, date, duration, temperature and energy cell status of over 1500 firings. Powered by lithium energy cells with a 10-year shelf life, the $X_{2} 6$ is the taser of choice for most police departments and retails for US\$799. TASER International, Inc., says it has sold the devices to 175 Canadian law enforcement agencies.

A controversial condition, "excited delirium" has been defined as being characterized by agitation, incoherence, bizarre behaviour, high temperature, superhuman strength, a high tolerance for pain - and sometimes, the compulsion to break or bang on glass. Those who study it say it can be brought on by drug use, alcohol withdrawal, low blood sugar, mental illness or extreme fatigue. It does not, however, appear in the American Psychiatric Association's Diagnostic and Statistical Manual of Mental Disorders (DSM).

But "delirium" - minus the "excited"- does.

Dr. Ian Dawe, director of Psychiatric Emergency Services at St. Michael's Hospital in Toronto, explains delirium as "a fluctuating level of consciousness," a set of symptoms that stereotypically appear together as a result of intoxication or an underlying medical condition.

The DSM says most sufferers of delirium fully recover but some don't as "delirium may progress to stupor, coma, seizures, or death, particularly if the underlying cause is untreated."

Dawe says there are 2 kinds of delirium: active and hypoactive. People suffering from the former might behave more or less as Dziekanski did: they can be agitated, irrational, and hard to communicate with. The hypoactive form, meanwhile, makes people quiet and withdrawn.
Active delirium can increase risks associated with physical restraints, Dawe says. But when someone suffering from delirium dies, determining the cause is problematic. Was it delirium? The taser? Restraint? A complex interplay of all the above?

Dawe says "excited delirium" is a pop culture phenomenon and doesn't have much currency among psychiatrists, although police, coroners and forensic pathologists use it.

University of Miami Professor of Neurology Dr. Deborah Mash, who has studied the condition for 20 years, says "sudden death in the context of emotional stress is well-known. Just because there isn't something called 'agitated delirium' or 'excited delirium' - that vernacular is not in the DSM-IV - doesn't mean that the symptom set is not in the DSM, because it is. We have evidence to suggest it's a brain disease."

Mash argues the condition is the result of an interaction between genes and environment: the gene remains silent until triggered by something like alcohol, drugs, stress or sleep deprivation anything that affects dopamine. "It's always the same. The presentation is the same, the behavioural syndrome is the same, the hyperthermia is there, and the phenomenon of sudden death is there. And it doesn't matter whether they were restrained, or hogtied, or pepper sprayed or tasered - it's the same." 
"This is a condition where law enforcement doesn't have a lot of options ... now, if you just left someone with excited delirium in the woods, I mean, what would happen to them? We don't know the answer. We've had purported excited delirium deaths where there were no police involved."

Yet, here's the rub. Those who die of "excited delirium" usually do so while in police custody, often after having been tasered.

To be sure, it's not a disease invented by the RCMP. In fact, they are late to the adoption of "excited delirium" as a condition. As early as I849, Dr. Luther Bell described the inexplicable sudden death of psychotic patients as "acute exhaustive mania," while
Dr. Charles Wetli coined the term "excited delirium" in 1985 to explain sudden death in recreational cocaine users.

Yet, so convinced are police that "excited delirium" is a legitimate condition that PoliceOne.com, an international information website for police officers, includes a direct link to an excited delirium training video created by the Las Vegas Police Department. In the video, Sherriff Bill Young even asserts that excited delirium leads people to blame police for deaths they didn't cause.

The video explicitly recommends using tasers to override the central nervous system, incapacitating the suspect just long enough for officers to properly restrain him. In a dramatization, a handcuffed suspect lies on the ground, sur-

\section{Box 1: Tasers}

\section{Basics}

The trademarked name TASER $®$ is an acronym for the "Thomas A. Swift Electric Rifle," the name given to the electroshock weapon invented by Jack Cover as a means of incapacitating people by causing temporary paralysis. Tasers use compressed nitrogen to propel 2 electrodes that are connected to the weapon by conductive wire. An electrical signal is then passed through the wires to the point where the probes, which travel at a speed of over $48.76 \mathrm{~m}$ per second, make contact with the target's body or clothing. Manufacturers say that while the device produces 50000 volts, "only short pulses of 400 volts actually enter the body." The average electrical current delivered is pegged at 0.0021 amperes.

Models

There are 2 main police models, the X26 and M26 (and variants therein). TASER International has recently begun marketing a new civilian model almost as a fashion accessory, coming in "leopard print" or colours like "metallic pink" and "electric blue." Among other options is the TASER shockwave, which simultaneously fires 6 cartridges to "saturate" an area. Under development is the XREP, a wireless taser round that can be fired from a 12-gauge shotgun.

\section{Range}

Depending on the type of cartridge used, tasers can be deployed for up to $10.67 \mathrm{~m}$, although the range for stun guns sold to civilians is about half that.

Cost

The basic TASER X26, the preferred electronic control device of police officers, retails for a brisk US\$799.95. New “consumer” models range from US\$299 to US\$349.

\section{Buyers}

TASER International says it has sold over 301000 weapons to over 12000 law enforcement and military agencies worldwide, including 175 Canadian law enforcement agencies. The company says it has sold 160000 tasers to individuals. Theoretically, none of those sales have occurred in Canada, where tasers are prohibited, except for law enforcement agencies. The firm says an average 490 tasers are fired daily and that field stats indicate tasers have been used on 470000 suspects worldwide.

Deaths

TASER International once marketed the devices as "non-injurious" but, as a result of a series of legal imbroglios, now markets the guns as a way to "protect life" by using technology that "minimizes the risk of serious injury." According to Amnesty International, 310 North Americans have died since 2001 after being shot with a taser. The fatality rate per use of the device is unavailable.

rounded by 7 officers. They place no weight on him and eventually turn him on his back and sit him upright. Nothing is done that might constrain the suspect's breathing, a point PoliceOne.com is careful to caution against.

The latter is by no means moot the link between restraint, excited delirium and oxygen supply has long been the subject of debate and concern.

A 1998 review of 2I cases of unexpected deaths in people in a state of excited delirum - I8 of which were people in police custody - found that all "suddenly lapsed into tranquility shortly after being restrained (CMAJ I998:I58 [12]: I603-07). In all 2I cases, the victims had been restrained either face-down or through pressure applied to their necks. In 12 cases, excited delirium was brought on by a psychiatric disorder. In 8 cases, cocaine was the culprit. In 8 cases, the victims suffered chest compression from the weight of $\mathrm{I}-5$ people.

The study concluded that "the possibility that positional asphyxia contributes to unexpected death in people in states of excited delirium cannot be ignored." Those suffering from excited delirium were in need of more than the usual amount of oxygen, yet the techniques used to restrain them could restrict their ability to breathe.

Dawe is sympathetic to people faced with the task of controlling situations like Dziekanski's. "I wouldn't want to lay blame on anyone." He'd like to enhance cooperation between police, paramedics and mental-health professionals, so that police could have "a broader range of options" when dealing with such cases. St. Michael's has partnered up with 2 downtown Toronto police divisions to create a "mobile crisis intervention team" - a constable and a mental-health nurse who deal with 9II dispatches involving emotionally disturbed people. The idea is to decriminalize mental health issues and reduce visits to the prison and the hospital.

"If something good can come out of tragedy, it's that perhaps we can develop a different approach to these situations," Dawe adds. - Amanda Truscott, Ottawa, Ont. 